\title{
A Case of Dapsone Poisoning in Eight Year Old Child
}

\section{Edwin Dias}

Professor and HOD, Department of Paediatrics, Srinivas Institute of Medical Sciences \&

Research Centre, Mangalore, India

E-mail: dredwindias@gmail.com

Type of the Paper: Medical Case Study.

Type of Review: Peer Reviewed.

Indexed In: OpenAIRE.

DOI: http://dx.doi.org/10.5281/zenodo.847173.

Google Scholar Citation: IJHSP

\section{How to Cite this Paper:}

Dias, Edwin. (2017). A Case of Dapsone Poisoning in eight year old child. International Journal of Health Sciences and Pharmacy (IJHSP), 1(2), 16-18.

DOI: http://dx.doi.org/10.5281/zenodo.847173.

International Journal of Health Sciences and Pharmacy (IJHSP)

A Refereed International Journal

(C) With Authors.

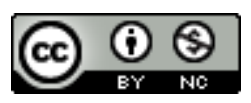

This work is licensed under a Creative Commons Attribution-Non Commercial 4.0 International License subject to proper citation to the publication source of the work.

Disclaimer: The scholarly papers as reviewed and published by the Srinivas Publications (S.P.), India are the views and opinions of their respective authors and are not the views or opinions of the SP. The SP disclaims of any harm or loss caused due to the published content to any party. 


\title{
A Case of Dapsone Poisoning in Eight Year Old Child
}

\author{
Edwin Dias \\ Professor and HOD, Department of Paediatrics, Srinivas Institute of Medical Sciences \& \\ Research Centre, Mangalore, India \\ E-mail: dredwindias@gmail.com
}

\begin{abstract}
An eight year old child was admitted with breathing difficulty and ingestion of ten dapsone tablets, on examination cyanosis was detected and methemoglobinemia was found. The child was treated with supportive measures intravenous methylene blue and ascorbic acid as the methemoglobinemia did not reduce to an acceptable level, an exchange transfusion was done the child improved gradually.
\end{abstract}

Keywords: Breathing difficulty, Dapsone, Cyanosis, Methemoglobinemia.

\section{INTRODUCTION :}

Dapsone (DDS-diaminodiphenylsulphone), is a sulfone antibiotic used in the treatment of leprosy and for dermatological disorders [1]. Although dapsone poisoning was more frequent in the past [2], it is becoming less common in children. There are only few case reports on dapsone poisoning in children in recent years [3-7]. The most frequent complication of dapsone poisoning in children is hemolytic anemia and methemoglobinemia [8]. The level of methemoglobinemia determines the poisoning symptoms and severity. At the lowest level of methemoglobinemia $(<30 \%)$, child could be asymptomatic; as the level increases it may present with headache, lethargy, tachycardia, dizziness may occur (3). Further increase in methemoglobinemia may result in progressively dyspnea, acidosis, seizures, cardiac dysrhythmias, heart failure, coma and even death when methemoglobinemia is high $(<70 \%)$ [3]. The treatment of dapsone intoxication is oral administration of activated charcoal and intravenous administration of methylene blue for symptomatic methemoglobinemia. Gastric decontamination and early administration of serial oral activated charcoal is effective in reducing further absorption. Although, hemolysis can be mild, transfusions may be required for patients with a glucose-6-phosphate dehydrogenase deficiency (6) or in situations where methemoglobinemia is not controlled. Below a case of Dapsone poisoning in 8 year old child is presented.

\section{CASE REPORT :}

8 Year old child presented with irritablilty, restlessness, breathing difficulty 1 day prior to accidental ingestion of 10 dapsone tablets. The drugs has been taken by father for the treatment of leprosy. Child had bluish discolouration of lips and tongue. On examination revealed central cyanosis,pulse rate of 116beats/ min regular, good volume, respiratory rate of 48 breaths/min with intercostal and subcostal recession, BP 100/60 $\mathrm{mm} \mathrm{Hg}$. Systemic examination was showed to have PEM, Weight was $16 \mathrm{~kg}$ and Height was $112 \mathrm{~cm}$, Blood was drawn for investigation was chocolate brown in colour, it did not change colour when oxygen was bubbled through it. Haemoglobin-8 mg/dl, blood urea$42 \mathrm{mg} / \mathrm{dl}$, serum electrolytes $\mathrm{Na}^{+}-137, \mathrm{~K}^{+}-$ 4.2,chest $\mathrm{x}$ ray and ECG were normal.ABG was normal. Methemoglobin level was $20 \%$ at admission. Child was started supportive treatment and gastric lavage. The child was admitted and given activated charcoal orally with immediate intravenous administration of methylene blueat $2 \mathrm{mg} / \mathrm{kg}$ of $1 \%$ solution. Half of the initial dose was repeated after 5hrs, child did not show much improvement methylene blue level decreased to $15 \%$. Correction of metabolic acidosis and administration of Ascorbic acid $500 \mathrm{mg}$ intravenously was given, intravenous ascorbic 
acid $100 \mathrm{mg}$ twice daily was continued. Inspite of the treatment Methemogoblin level was not reduced. Exchange transfusion was done after Methemoglobin is drop to $10 \%$ and child improved drastically thereafter. On follow up no sequelae were found.

\section{DISCUSSION :}

Accidental dapsone is a paediatric emergency in young preschool children [2]. Dapsone a sulfone is well absorbed on oral ingestion with peak levels after two or three hours. The drug can be detected in tissues up to three weeks after ingestion. It causes methemoglobinemia resulting in cyanosis. The clinical symptoms vary and depend upon on methemoglobin concentration in blood [9]. Methemogloblin is incapable of binding oxygen and also increases the affinity for unaltered haemoglobin for oxygen ,shifting the oxygen dissociation curve to left thus further improving oxygen delivery resulting in dyspnoea. The CNS manifestations are irritability, hypotonia, truncalataxia, chorieform movements and dysarthritic speech $[4,7]$.

Direct effect of drug on CNS and cerebral anoxia is due to methemoglobinemia. In acute dapsone toxicity initial attempts should be given to gut decontamination. And improvement of oxygen delivery, main emphasis on administration of methylene blue and ascorbicacid. Metheylene blue given intra venous is rapidly reduced in to leukomethylene blue then becomes available to reduce methemoglobin to haemoglobin. It is the mainstay of the treatment of methemoglobinemia. In less severe cases ascorbic acid 200-500mg can be given iv (3).exchange transfusion can be tried in a cases not responding to methylene blue [9].

It is suggested that cases previously perfectly normal and presenting with unexplained central cyanosis with history of ingestion of dapsone be considered as having Methemoglobinemia. Dapsone a commonly used drug in the treatment of leprosy should be kept out of reach of children to prevent significant morbidity and mortality. Exchange transfusion had been reported to be very effective in the management of Methemog Iobinemia (9).

\section{CONCLUSION :}

In this child prompt treatment of methemoglobinemia with methylene blue and ascorbic acid, with exchange transfusion was efficacious.

\section{REFERENCES :}

[1] Zhu Y I, Stiller M J. Dapsone and sulfones in dermatology: overview and update. Journal of the American Academy of Dermatology. 2001; 45(3):420-34.

[2] Nair P M, Philip E. Accidental dapsone poisoning in children. Annals of tropical paediatrics. 1984; 4(4):241-2.

[3] Sunilkumar M N, Ajith T A, Parvathy V $\mathrm{K}$. Acute Dapsone poisoning in a 3-yearold child: Case report with review of literature. World journal of clinical cases. 2015; 3(10):911-4.

[4] MacDonald R D, McGuigan M A. Acute dapsone intoxication: a pediatric case report. Pediatric emergency care. 1997; 13(2):127-9.

[5] Gomber S, Singh R P, Chawla R, Gupta $\mathrm{R}$, Sharma S. Accidental dapsone poisoning in children. Indian pediatrics. 1994; 31(9):1123-5.

[6] Hansen D G, Challoner K R, Smith D E. Dapsone intoxication: Two case reports. The Journal of emergency medicine. 1994; 12(3):347-51.

[7] O'Dwyer D, McElvaney N G. A case of dapsone induced methaemoglobinaemia. Irish journal of medical science. 2008; 177(3):273-5.

[8] Barclay J A, Ziemba S E, Ibrahim R B. Dapsone-induced methemoglobinemia: a primer for clinicians. The Annals of pharmacotherapy. 2011; 45(9):1103-15.

[9] Kumar A, Antony T J ,Jurien K M, Taneja L N, Manmohan ,Anand N K. Exchange transfusion for dapsone poisoning.Indian Pediatrics 1988, 25;798-800. 